\title{
Importance of vertical velocity variations in the cloud droplet nucleation process of marine stratus clouds
}

\author{
Yiran Peng, ${ }^{1,2}$ Ulrike Lohmann, ${ }^{1,3}$ and Richard Leaitch ${ }^{4}$ \\ Received 19 August 2004; revised 8 July 2005; accepted 31 August 2005; published 12 November 2005.
}

[1] Eleven cloud cases through marine stratus, obtained during two field experiments in the North Atlantic Ocean, are used to study the sensitivity of cloud droplet nucleation to the vertical gust velocity. Selected cloud microphysical data, size-distributed aerosol properties and particle chemistry are applied in an adiabatic parcel model. The nucleated cloud droplet number concentrations $(N)$ predicted using the probability density function (PDF) of the measured in-cloud vertical velocities are compared to predictions using a characteristic velocity value. In this study, the model-predicted $N$ from the PDF of the measured in-cloud vertical velocities agrees with the observed maximum $N\left(N_{\max }\right)$ to within $8.6 \%$. The average $N\left(N_{a v g}\right)$ can be related to $N_{\max }$ using a power law (Leaitch et al., 1996). If a relationship between $N_{\max }$ and $N_{\text {avg }}$ based on the measurements is applied to obtain the average $N$ from the model-predicted $N$, then the model-predicted average $N$ agrees with the observed average $N$ to within $13.3 \%$. When a characteristic vertical velocity ( 0.8 times the standard deviation of the vertical velocity distribution in this study) is used in the parcel model to simulate $N$, the model-predicted $N$ agrees with the observed maximum $N$ to within $5.7 \%$ and the model-predicted average $N$ agrees with the observed average $N$ within $8.8 \%$. This indicates that using a characteristic value of the vertical velocity distribution instead of its PDF is a good approximation for simulating the nucleated cloud droplet number of marine stratus on a cloud scale.

Citation: Peng, Y., U. Lohmann, and R. Leaitch (2005), Importance of vertical velocity variations in the cloud droplet nucleation process of marine stratus clouds, J. Geophys. Res., 110, D21213, doi:10.1029/2004JD004922.

\section{Introduction}

[2] An increase in the cloud droplet number concentration $(N)$ due to anthropogenic emission of aerosol particles and their precursors can enhance the cloud reflectivity and prolong the lifetime of the cloud by reducing precipitation [e.g., Lohmann et al., 2000; Peng et al., 2002]. This, the indirect effect of the atmospheric aerosol, is a major uncertainty in the balance of radiative forcing of the atmosphere by chemical constituents [Houghton et al., 2001]. The prediction of $N$ in a general circulation model (GCM) with appropriate accuracy is an important factor in assessing the indirect effect of aerosols on the global climate [Boucher and Lohmann, 1995]. Cloud droplets are formed by the activation of aerosol particles in clouds, and are lost by evaporation, collision/coalescence and accretion by rain drops and snow flakes. A prognostic equation that includes these microphysical processes is applied in some climate

\footnotetext{
${ }^{1}$ Department of Physics and Atmospheric Science, Dalhousie University, Halifax, Nova Scotia, Canada.

${ }^{2}$ Now at Max Planck Institute for Meteorology, Hamburg, Germany.

${ }^{3}$ Now at Institute for Atmospheric and Climate Science, Swiss Federal Institution for Technology (ETH), Zurich, Switzerland.

${ }^{4}$ Meteorological Service of Canada, Downsview, Ontario, Canada.

Copyright 2005 by the American Geophysical Union. 0148-0227/05/2004JD004922\$09.00
}

models [Lohmann et al., 1999; Ghan et al., 1997] to calculate the grid mean $N$.

[3] The aerosol activation process to form cloud droplets on inorganic aerosols is theoretically well understood [Pruppacher and Klett, 1997; Seinfeld and Pandis, 1998]. Squires and Twomey [1960] developed the first parameterization of aerosol activation assuming the activated particle number depends on the supersaturation following a power law. This has later been modified by Cohard et al. [1998] in terms of parameters of the lognormally distributed cloud nuclei number concentration, since measured aerosol size distributions are more realistically represented by multiple lognormal spectra [Whitby, 1978].

[4] Twomey's parameterization was further improved when Ghan et al. [1993, 1995] developed a parameterization of the number concentration of droplets nucleated in a cloud as a function of vertical velocity, aerosol number concentration, aerosol composition, mode radius and the standard deviation of the aerosol size distribution. In this parameterization, the size of aerosol particles is expressed as a function of their critical supersaturations based on Köhler theory, assuming each particle is instantaneously in equilibrium with its environment (equilibrium approximation). The growth equation of particles is combined with the rate of change of the supersaturation, which is induced by the uplifting air parcel and depleted by the condensation of water vapor on activated particles and their subsequent growth. The maximum supersaturation at which the maxi- 
mum number of particles is activated can be derived assuming aerosol particles are lognormally distributed, as generally obtained from observations. Abdul-Razzak et al. [1998] and Abdul-Razzak and Ghan [2000, 2002] extended this method to the case of multiple aerosol types (which can be internally or externally mixed or be a combination of both) and to a sectional representation of the aerosol size distribution which can readily be applied in a large-scale model. These parameterized results are compared with simulations using a detailed computational model for a rising air parcel. Good consistencies are shown for a large variety of parameters.

[5] A shortcoming with the parameterization developed by Ghan et al. [1993, 1995] is the equilibrium approximation. With this assumption the size of particles is described in relation to their critical supersaturation. This ignores the kinetic delay of growth of particles to reach the equilibrium size. The neglect of this kinetic effect (kinetic limitation) of droplet growth tends to underestimate $N$ because it overestimates the size and water uptake by large particles and inhibits possible growth of small particles to form cloud droplets.

[6] Phinney et al. [2003] compared $N$ predicted using Ghan's parameterization which neglects kinetic effects [Abdul-Razzak and Ghan, 2000] and $N$ simulated with a parcel model. The parcel model explicitly solves the growth rate of the size of particles and thus accounts for the time required for reaching the equilibrium size (kinetic effect). Their results indicate that the kinetic effect is of significant importance for conditions of low updraft velocities $\left(<0.5 \mathrm{~m} \mathrm{~s}^{-1}\right)$ and high aerosol number concentrations $\left(>500 \mathrm{~cm}^{-3}\right)$. Marine stratus clouds typically have characteristic vertical velocities between 0.1 and $0.6 \mathrm{~m} \mathrm{~s}^{-1}$ [Guibert et al., 2003]. Thus parcel models not constrained by the equilibrium assumption may be better suited for describing the droplet activation compared to those which ignore the kinetic effect [e.g., Abdul-Razzak and Ghan, 2000].

[7] The simple form of the parameterization of aerosol activation derived by Ghan et al. [1993] has been used in previous GCM studies [e.g., Ghan et al., 1997; Lohmann et al., 1999]. It can be integrated over the probability density distribution of vertical velocities in a GCM grid cell in an attempt to account for the subgrid-scale variability in vertical velocity. Lin and Leaitch [1997] examined Ghan's parameterization against observations and found that it might only be appropriate to estimate $N$ in the updraft where the cloud water content can be assumed to be adiabatic. They also derived an empirical relationship between the maximum $N\left(N_{\max }\right)$ and the averaged $N\left(N_{a v g}\right)$ from the observational data taken over the Bay of Fundy and the Gulf of Maine [Leaitch et al., 1996] to obtain $N_{\text {avg }}$ from $N_{\max }$ of marine stratus clouds.

[8] The grid size in a GCM is much larger than the scale of the turbulent and mesoscale processes that produce small-scale fluctuation of vertical velocities (i.e., cloud scale). Thus $N$ calculated only from the grid mean vertical velocity in the GCM is a simplification in which the subgrid-scale variability of vertical velocity is ignored. Observational evidence [Leaitch et al., 1996; Brenguier et al., 2000] shows that the variation of vertical motions is strongly related to the nucleated number of cloud droplets.
To represent the fluctuation of in-cloud vertical motions within a grid cell, Ghan et al. [1997] and Chuang et al. [1997] used a probability density function $(p(w)$, cf. Figure 4 of this paper) of normally distributed vertical velocities parameterized in terms of the grid cell mean and the subgrid-scale variance of vertical velocity to obtain $N$ within a grid box from the integral of $p(w) N(w) d w$. Alternatively, the turbulent kinetic energy (TKE) is used as a surrogate for the subgrid-scale variance of the vertical velocity [Lohmann et al., 1999] in the GCM.

[9] Snider et al. [2003] discussed the discrepancy between parcel model simulated $N$ integrated over the in-cloud vertical velocity distribution and observed $N$ from cloud microphysical measurements obtained during the second Aerosol Characterization Experiment (ACE-2). The predicted $N$ from Snider et al. [2003] is simulated using an adiabatic parcel model, initialized with a normalized vertical velocity probability density function and the measured cloud condensation nuclei ( $\mathrm{CCN})$ spectrum. Compared with the adiabatic $N$ obtained from observations [Pawlowska and Brenguier, 2000], the predicted $N$ of five cloud cases generally agrees with observed adiabatic $N$ within $\pm 30 \%$. The predicted $\mathrm{N}$ is insensitive to the bias of the observed $\mathrm{CCN}$ spectrum due to the measurement uncertainties. However, if the measured $\mathrm{CCN}$ spectrum is replaced by observed aerosol physical and chemical properties to initialize the parcel model, the predicted $N$ generally overestimates observed adiabatic $N$. Several possible explanations were analyzed by Snider et al. [2003] in terms of representations of size distribution and soluble fraction of aerosols, vertical velocities and the measured $N$, trying to find the reason for the larger discrepancy in $N$ when measured aerosol properties replaced the $\mathrm{CCN}$ information as the model input. However, none of these factors is individually responsible for the overall overestimation of $N$. One possible contributing factor could be the existence of particles covered by substances which limit the rate of condensational growth. This would challenge the traditional theory for calculating $N$ at the maximum supersaturation [Feingold and Chuang, 2002].

[10] In this paper, observed $N$ from a number of cloud cases is compared with the parcel model simulated $N$, using one characteristic vertical velocity, or using the probability density distribution of the vertical velocity similar to the approach applied by Snider et al. [2003]. The aim is to investigate the importance of vertical velocity variation in the cloud droplet nucleation process and to justify current methods to represent the fluctuation of vertical velocity in the parameterization of $N$ in GCMs. Microphysical data of marine stratus clouds are obtained during the Radiation, Aerosol and Cloud Experiment (RACE) and the North Atlantic Regional Experiment (NARE). Both are described in section 2 followed by the parcel model description and the analysis of its input data in section 3. The comparison of simulated and observed $N$ as well as the discussion of the sensitivity of $N$ to different parameters are given in section 4 , followed by conclusions in section 5 .

\section{Data Description}

[11] The data discussed here were taken from RACE and NARE projects. RACE took place in fall 1995 off the coast 
Table 1. Instrumentation During RACE and NARE ${ }^{\mathrm{a}}$

\begin{tabular}{lcccc}
\hline & TW 1-s & TW Filter & CON 1-s & CON Filter \\
\hline \multirow{4}{*}{ LWC } & & $R A C E$ & & \\
$N_{a} 3025$ & yes & n/a & yes & n/a \\
$N_{a}$ & yes & n/a & n/a & n/a \\
$w$ & yes & yes & yes & yes \\
$N$ & yes & n/a & n/a & n/a \\
$\epsilon$ & yes & n/a & yes & n/a \\
$N_{a}$ size & n/a & yes & n/a & yes \\
& yes & n/a & yes & yes \\
& & & & \\
LWC & & $N A R E$ & & $n$ \\
$N_{a} 3025$ & yes & n/a & n/a & n/a \\
$N_{a}$ & yes & n/a & n/a & n/a \\
$w$ & yes & yes & n/a & n/a \\
$N$ & yes & n/a & n/a & n/a \\
$\epsilon$ & n/a & yes & n/a & n/a \\
$N_{a}$ size & yes & n/a & n/a & n/a \\
\hline
\end{tabular}

${ }^{\mathrm{a}}$ Shown are availability of cloud liquid water content $\left(L W C\right.$ in $\left.\mathrm{g} \mathrm{m}^{-3}\right)$, aerosol number concentration measured with the TSI3025 UCPC $\left(N_{a} 3025\right.$ in $\mathrm{cm}^{-3}$, including Aitken mode aerosols), aerosol number concentration measured with the PCASP/ASASP $\left(N_{a}\right.$ in $\mathrm{cm}^{-3}$, for accumulation mode aerosols), vertical velocity ( $w$ in $\mathrm{m} \mathrm{s}^{-1}$ ), cloud droplet number concentration $\left(N\right.$ in $\left.\mathrm{cm}^{-3}\right)$, water soluble fraction of aerosols $(\epsilon)$ and the size distribution of accumulation mode aerosols $\left(N_{a}\right.$ size $)$. TW 1-s is the 1-s averaged Twin Otter data. TW filter is the Twin Otter measurements averaged over the filter sampling intervals. CON 1-s and CON filter are similarly identified for measurements on the Convair 580 aircraft.

of Nova Scotia, Canada [Li et al., 1998]. Two aircraft were used as the measurement platforms: the National Research Council of Canada (NRCC) Twin Otter and Convair 580. Aerosol and cloud microphysical and chemical data were measured on both aircraft [Peng et al., 2002; Li et al., 1998].

[12] During NARE the NRCC Twin Otter was used to conduct chemical and microphysical measurements of aerosols and clouds in marine stratus off the southern end of the Nova Scotia in the late summer of 1993 [Fehsenfeld et al., 1996; Li et al., 1996].

[13] Table 1 outlines the instrumentation during RACE and NARE. The vertical velocity $(w)$ measurements were obtained from a 5-axes gust probe on the nose of the Twin Otter. The variation of in-cloud $w\left(\sigma_{w}\right.$, i.e., the standard deviation of $w$ distribution over the in-cloud region) is used to describe the turbulence in clouds. The uncertainty of the measured vertical velocity is $\pm 0.05 \mathrm{~m} \mathrm{~s}^{-1}$ [Leaitch et al., 1996].

[14] In RACE, the total aerosol number concentration including Aitken mode aerosols $\left(N_{a} 3025\right.$, cf. Table 1$)$ and the number concentration of the accumulation mode aerosols $\left(N_{a}\right)$ were measured with a TSI3025 Ultrafine Condensation Particle Counter (UCPC) and a Particle Measuring System (PMS) Passive Cavity Aerosol Spectrometer Probe (PCASP), respectively, on the Twin Otter. $N_{a}$ was also measured with a PMS Active Scattering Aerosol Spectrometer Probe (ASASP) on the Convair 580 aircraft [ $\mathrm{Li}$ et al., 1998]. Cloud liquid water content ( $L W C$ ) was measured using a PMS King hot-wire probe on the Twin Otter and a Nevzorov liquid water probe on the Convair 580 aircraft. The cloud droplet number concentration $(N)$ on both aircraft were obtained with PMS Forward Scattering Spectrometer Probe (FSSP) as described by Peng et al. [2002]. All of the above measurements were taken as 1-s averages for application in this study.

[15] Low-volume Teflon filters were used on both the Twin Otter and the Convair 580 aircraft to collect aerosol samples for analysis by ion chromatography (IC) to provide data on the inorganic chemical composition of aerosols in RACE. Some limited data on the water soluble organic composition were also obtained from the IC analysis [ $\mathrm{Li}$ et al., 1996]. Measurements obtained from the filters on the Convair 580 are averaged over shorter time periods than the Twin Otter measurements and are better aligned with the microphysical measurements in and below clouds. Thus the filter data from the Convair 580 aircraft are used for the aerosol chemical composition where possible. Hereafter the 1-s averaged Twin Otter data are referred to as the TW 1-s data, and the Twin Otter measurements averaged over the filter sampling intervals are referred to as the TW filter data. The Convair 580 measurements are similarly identified as the CON 1 -s and CON filter data.

\section{Model Description and Analysis of Its Input Data}

\subsection{Parcel Model}

[16] An adiabatic parcel model described by Leaitch et al. [1986] and used by Phinney et al. [2003] is applied in this study to simulate the nucleation of cloud droplets on aerosol particles with a prescribed updraft velocity. Assuming an air parcel ascending adiabatically (no entrainment or drizzle formation is taken into account in this parcel model) with a constant updraft velocity, the model calculates the supersaturation based on the diffusional growth equation following Pruppacher and Klett [1997]. Condensation of water vapor on droplets reduces the supersaturation and increases the cloud droplet size and cloud liquid water content. $N$ is determined after the supersaturation is beyond its maximum value.

[17] The nucleation process in the parcel model is initiated from multiple aerosol distributions with a defined chemical composition in each size mode. A trimodal lognormal distribution was fitted to the aircraft measurements using different dried aerosol counters. The soluble and insoluble components of particles were estimated from the chemistry data. The rate of change of the solution particle radius is explicitly solved within each time interval in the parcel model. Thus a possible underestimation of $N$ due to the neglect of the kinetic effect in the work by Abdul-Razzak and Ghan [2000] is avoided as discussed in the introduction and by Phinney et al. [2003]. A water condensation coefficient of 1.0 is used in this model as indicated by Leaitch et al. [1986]. The implications of this choice are discussed in section 4.2. Cloud droplets are defined as those particles with wet radii larger than $1 \mu \mathrm{m}$ having a positive growth rate. The number of nucleated cloud droplets to be compared with the observed $N$ is obtained at the maximum supersaturation, which in turn depends on the prescribed updraft velocity of the air parcel.

[18] Temperature and pressure of the air parcel below cloud base, required for the parcel model simulations, are obtained from observations. Observed relative humidity $(R H)$ at cloud base is between $95 \%$ and $98 \%$ for all cloud cases in this study. We use a relative humidity of $98 \%$ 

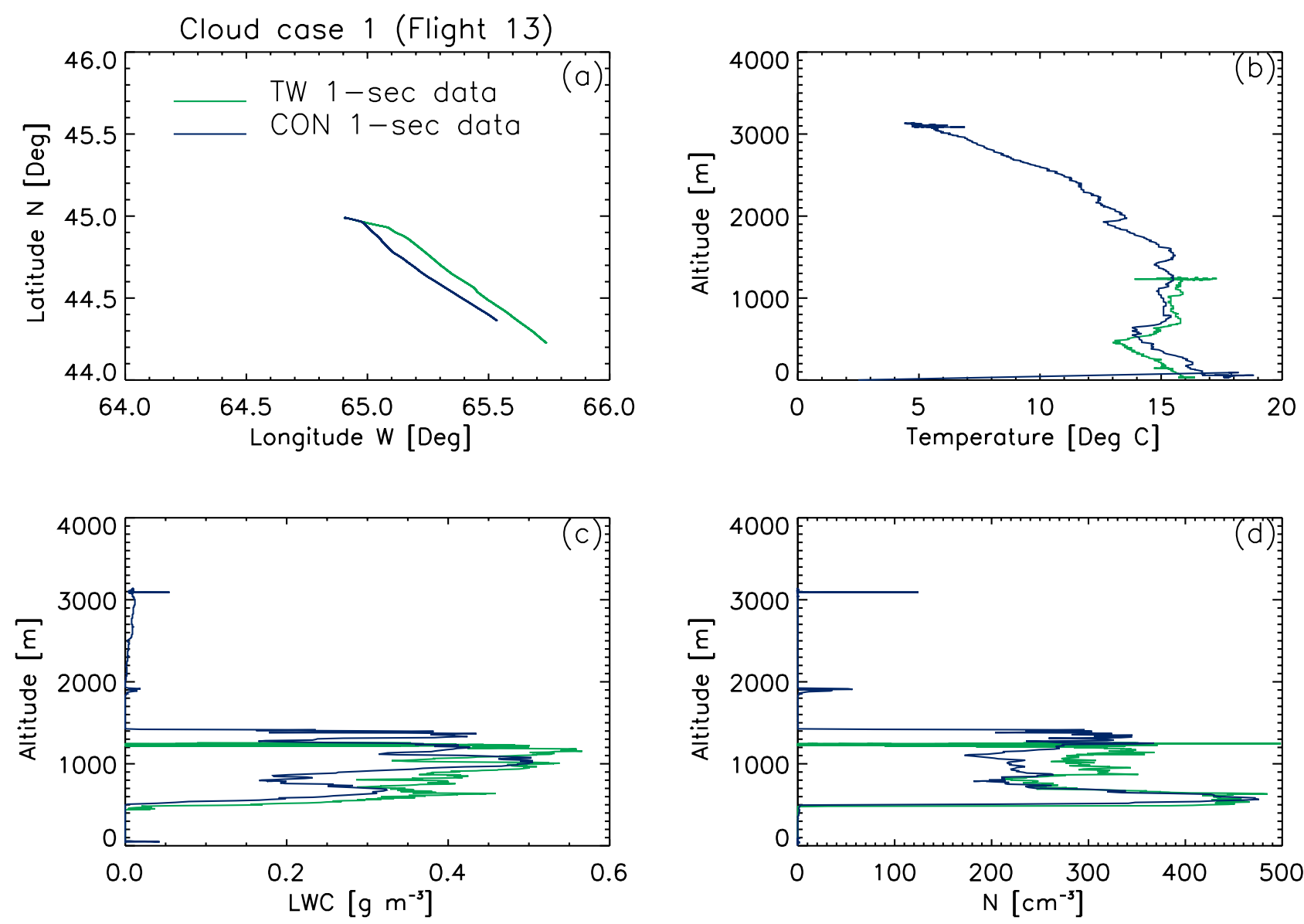

Figure 1. Data of cloud case 1 obtained from flight 13 during RACE. (a) Location, (b) temperature, (c) $L W C$ and (d) $N$ profiles obtained from the Twin Otter (green line) and Convair 580 aircraft (blue line).

uniformly to initialize the parcel model, which allows sufficient time for particles to reach their equilibrium size before the air parcel becomes saturated. Phinney et al. [2003] showed that a variation of the initial $R H$ between $95 \%$ and $99 \%$ results in an insignificant change in simulated $N$ using the same parcel model.

\subsection{RACE Data}

[19] Five cloud segments (cloud cases 1-3 from flight 13 and 4-5 from flight 18) during RACE are selected on the basis of the availability of a complete data set including cloud profile data, aerosol properties at cloud base and level flight in clouds for the vertical velocity. Data collected during an ascent and a following flat section in flight 13 are plotted in Figures $1-3$ to illustrate how the aircraft measurements are applied in the parcel model.

[20] Cloud case 1 is for the period from 11:39:00 to 12:09:00 UTC. Figure 1 shows that the Twin Otter and Convair 580 aircraft were well coordinated, penetrating and sampling the same cloud. Temperature and pressure (not shown) averaged over the cloud base layer are taken as the input for the parcel model. The profiles of $L W C$ (Figure 1c) and $N$ (Figure 1d) define the in-cloud region and distinguish the cloud base for obtaining the necessary aerosol information at cloud base.

[21] On the basis of the profile of $N$ shown in Figure 1d, the observed maximum $N$ (taken as the 95th percentile of the observed $N$ distribution to avoid possible instrumental error with extreme $N$ values) is obtained ( $\left.N_{\max }^{o b s}\right)$. Additionally the averaged $N\left(N_{a v g}^{o b s}\right)$ over the cloud profile which accounts for the effect of entrainment and possible influence of drizzle formation is calculated for comparison with the parcel model simulated $N$.

[22] Figures $2 \mathrm{a}$ and $2 \mathrm{~b}$ show the time series of $w$, ratio of measured $L W C$ to adiabatic $L W C$ ( $L W C_{a d i}$, which is calculated depending on the temperature, pressure at each cloud height [Brenguier, 1991] as in the work by Peng et al. [2002]), altitude and $N$ of cloud case 1 . The ascending leg starting at 11:42:00 UTC together with the level part until 11:54:00 UTC are the in-cloud region where $N>10 \mathrm{~cm}^{-3}$ and the variability of $w$ is relatively high (a more "turbulent" situation).

[23] Since the gust measurement is based on pressure difference, measurements during changes in altitude are difficult. Consequently, only $w$ data taken during the level part of the flight track are valid. Probability density distributions (PDF) of $w$ are plotted in Figures $2 \mathrm{c}$ and $2 \mathrm{~d}$. The histogram of $w$ in Figure 2c is collected from the level flight track over the in-cloud region shown by the solid green line in Figure 2a. The $w$ data in Figure $2 \mathrm{~d}$ are from outside cloud after 11:54:00 UTC. The mean vertical gust velocity averaged over a sufficiently long flight segment should be zero. Thus the centers of both histograms are shifted to the origin. The deviation of the mean from zero is caused by systematic 


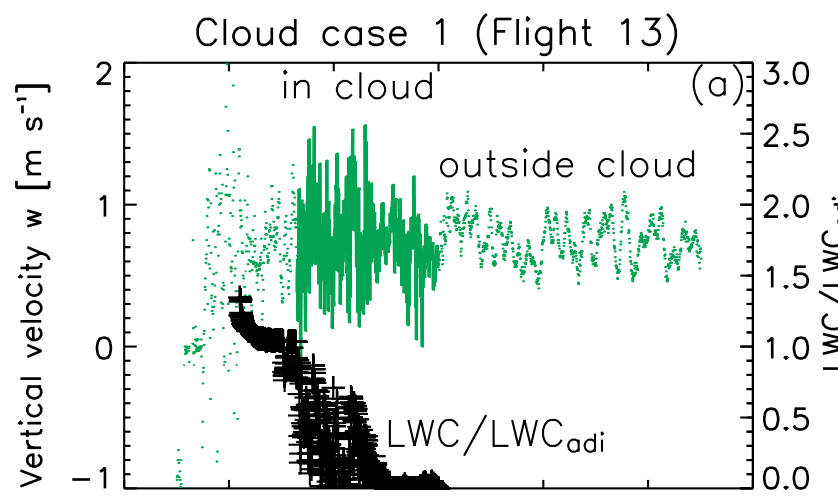

$\begin{array}{llllll}11: 36 & 11: 42 \quad 11: 48 \quad 11: 54 & 12: 00 & 12: 06 & 12: 12\end{array}$ Time (UTC)

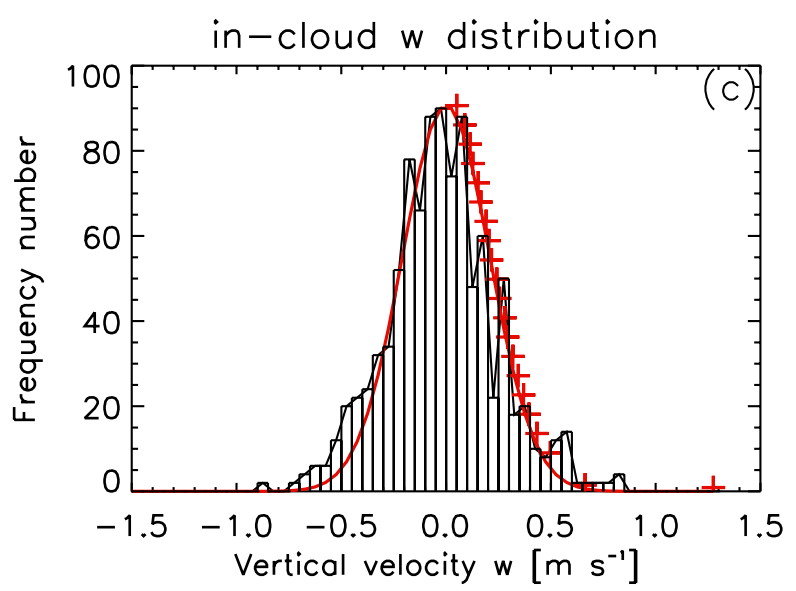

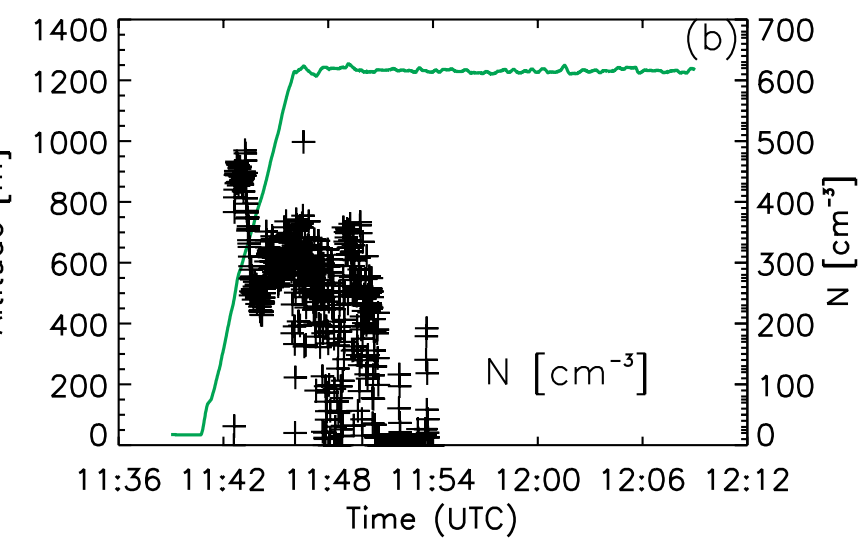

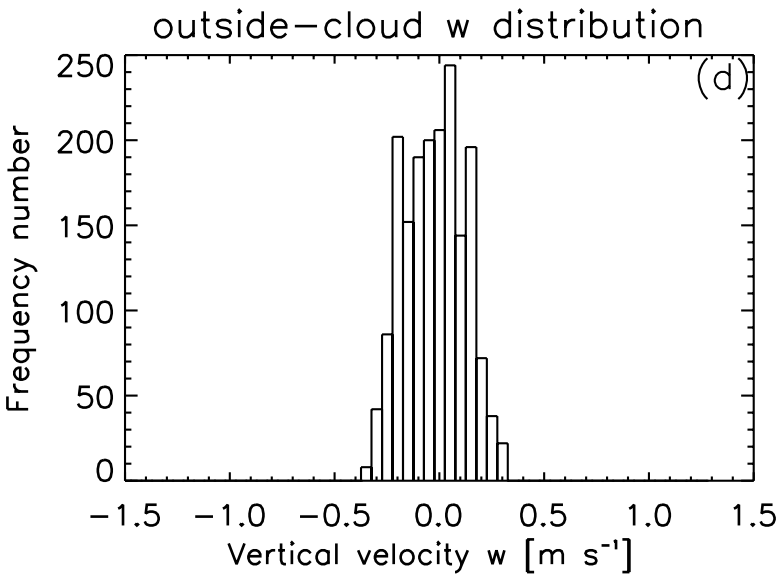

Figure 2. Vertical velocity measurements of cloud case 1: (a) time series of $w$ (green line and dots, lefthand side scale) and ratio of measured $L W C$ to adiabatic $L W C\left(L W C / L W C_{a d i}\right.$, black crosses, right-hand side scale) and (b) altitude (green line, left-hand side scale) and $N$ (black crosses, right-hand side scale) obtained from the Twin Otter 1-s measurement. Probability density function (PDF) of $w$ taken from (c) the in-cloud and (d) the outside-cloud region as indicated in Figure 2a. The PDF over the in-cloud region is fitted to a Gaussian distribution (red curve). Twenty-one vertical velocities are selected (red crosses) to simulate $N$ with the parcel model.

errors [e.g., Guibert et al., 2003]. The in-cloud region is characterized by a larger value of $\sigma_{w}$, indicating stronger turbulence comparing to the outside-cloud region.

[24] Mixing with the dry air at cloud edges may reduce $N$. To check if the deviation from adiabaticity influences the observed in-cloud quantities for this study, the variation of vertical velocities $\left(\sigma_{w}\right), N_{\max }^{o b s}$ and $N_{a v g}^{o b s}$ are derived from the region restricted by the adiabatic criterion $\left(L W C / L W C_{a d i}>\right.$ 0.8 ) in the level part and from the in-cloud region as shown in Figure $2 \mathrm{a}$ (where mixing processes deplete the liquid water content and may reduce $N$ or $w$ as well). Table 2 shows this comparison and indicates that both the variation of $w$ and $N$ are not significantly modified by deviations from adiabaticity. Because of the larger number of data points, the observed $w$ distribution, $N_{\max }^{o b s}$ and $N_{a v g}^{o b s}$ obtained from the entire in-cloud regions are used here.

[25] The dry aerosol particle size distributions for input to the model are obtained from just below cloud base. To illustrate, for cloud case $1, N_{a}$ within the 400-m thick layer below cloud base vary less than $30 \%$ (Figure $3 \mathrm{a}$ ) and the fluctuations of the potential temperature are less than $1 \mathrm{~K}$ within this layer. This is regarded as a well-mixed layer for which the one Convair 580 filter measurement is representative (cf. Figure 3a). Teflon filter samples collected on the Twin Otter and on the Convair 580 aircraft were analyzed by ion chromatography to give the mass concentrations of inorganic ions in the aerosol particles at altitudes of 400 and $250 \mathrm{~m}$ respectively. The sampling times were approximately $45 \mathrm{~min}$ to 1 hour (cf. the caption of Figure 3). $N_{a}$ from the Twin Otter and the Convair 580 during the filter measurements are similar near the cloud base (the orange circle and the red square in Figure 3a). The discrepancy between the 1-s data from the two aircraft (solid lines in Figure 3a) and the filter data (the orange circle and the red square) at the same altitude is due to differences in time and location. The high $N_{a}$ above the cloud (around $1500 \mathrm{~m}$ ) is the result of pollutants transported from the east coast of the U.S. [e.g., Li et al., 1998].

[26] Figure 3c shows the observed aerosol number size distribution averaged over the well-mixed layer below cloud base and the parameterized spectra used as input for the parcel model. The difference between $N_{a} 3025$ and $N_{a}$ measured with the PCASP is used to obtain the total particle number concentration in the Aitken mode for the parcel 

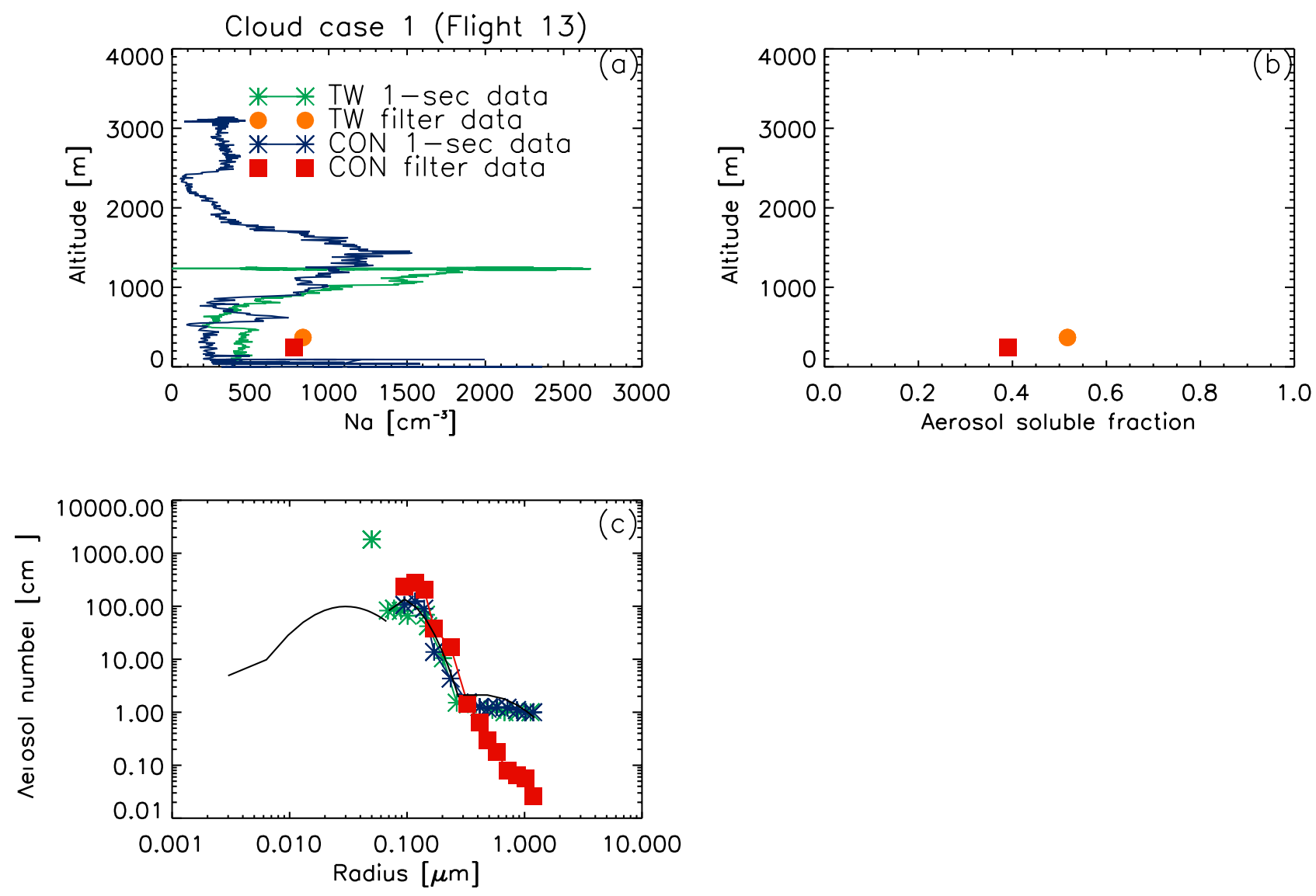

Figure 3. Aerosol properties of cloud case 1. (a) Aerosol number concentration profiles obtained from the Twin Otter (green) and the Convair 580 (blue) 1-s data. The orange circle and the red square denote $N_{a}$ from the filter measurements on the Twin Otter (averaged over the time period between 13:38:56 and 14:31:30 at the altitude of $400 \mathrm{~m}$ ) and Convair 580 aircraft (averaged over the time period between 13:01:50 and 13:45:13 UTC at 250 m), respectively. (b) Aerosol soluble fractions calculated from the filter measurements on the two different aircraft. (c) Total aerosol number concentration in the Aitken mode (the single green asterisk), the aerosol number concentration in each size bin of the accumulation mode from observations (connected asterisks and connected squares) and fits to a trimodal lognormal distribution (black solid curve). Note that the vertical axis is the number concentration of aerosol particles per bin in the accumulation mode and total aerosol number concentration for the Aitken mode.

model (the single green asterisk in the smallest mode in Figure 3c), which ranges from 0.003 to $0.07 \mu \mathrm{m}$ in radius. The mode radius and the standard deviation in this mode are assumed to be $0.05 \mu \mathrm{m}$ and 2, respectively [Abdul-Razzak and Ghan, 2000] (they are varied as discussed in section 4.2). The small accumulation mode falls in the range between 0.07 and $0.3 \mu \mathrm{m}$ in radius, and the large accumulation mode fits the tail of the distribution with radii between 0.3 and $1.4 \mu \mathrm{m}$. The total number concentrations of aerosols in these two modes are taken from observations and the mode radii are obtained from lognormal fits to the measured spectra. Each mode is divided into 33 size bins for application in the parcel model.

[27] Note that the 1-s measurements from the two aircraft and the Convair 580 filter data show a similar shape of the small accumulation mode of the aerosol spectrum (Figure $3 \mathrm{c}$ ), which is most important for cloud droplet nucleation (as it will be shown in section 4.2). The discrepancy between the PCASP/ASASP measured number concentration and the number concentration obtained from the Convair 580 filter is consistent with the difference of the measurements of the total aerosol number concentration on the different aircraft as shown in Figure 3a. This is attributed to the 1-s and the filter measurements being averaged over different times and locations.

[28] The ratio of the soluble ion mass $\left(\mathrm{NO}_{3}^{-}, \mathrm{SO}_{4}^{2-}, \mathrm{Cl}^{-}\right.$, $\mathrm{NH}_{4}^{+}, \mathrm{Na}^{+}$and the sum of water soluble organic ions based on the Convair 580 filter record) to the total aerosol mass (which is obtained from the PCASP measurement assuming the density of dry aerosols to be $1.55 \mathrm{~g} \mathrm{~cm}^{-3}$ [Li et al., 1996]) is calculated and shown in Figure 3b (the red square). The soluble mass fraction calculated on the basis of the Twin Otter filter measurement is shown as well (the orange circle). Generally soluble mass fractions obtained in RACE are between 0.4 and 0.6, comparable with those obtained during NARE (soluble ion mass as shown in Table 1 of [ $\mathrm{Li}$ et al., 1996]) taking into account the same soluble ions.

[29] Analysis of the samples from the filter measurements indicates that the water soluble salt composition of aerosol 
Table 2. Adiabaticity Check $^{\mathrm{a}}$

\begin{tabular}{|c|c|c|c|c|c|c|c|c|}
\hline \multirow[b]{2}{*}{ Cloud Case } & \multicolumn{4}{|c|}{ All } & \multicolumn{4}{|c|}{ Adiabatic } \\
\hline & $\sigma_{w}$ & $N_{\max }^{o b s}$ & $N_{\text {avg }}^{\text {obs }}$ & Number & $\sigma_{w}$ & $N_{\max }^{o b s}$ & $N_{\text {avg }}^{\text {obs }}$ & Number \\
\hline \multicolumn{9}{|c|}{$R A C E$} \\
\hline 01 & 0.26 & 440 & 262 & 487 & 0.32 & 453 & 314 & 11 \\
\hline 02 & 0.38 & 678 & 267 & 1621 & 0.39 & 677 & 265 & 791 \\
\hline 03 & 0.39 & 457 & 273 & 409 & 0.40 & 477 & 290 & 277 \\
\hline 04 & 0.26 & 147 & 46 & 1333 & 0.26 & 114 & 35 & 1333 \\
\hline 05 & 0.17 & 164 & 65 & 2161 & 0.19 & 159 & 95 & 46 \\
\hline \multicolumn{9}{|c|}{$N A R E$} \\
\hline 06 & 0.18 & 504 & 388 & 1189 & 0.19 & 504 & 387 & 1105 \\
\hline 07 & 0.08 & 439 & 198 & 901 & 0.08 & 439 & 198 & 901 \\
\hline 08 & 0.14 & 407 & 148 & 1153 & 0.14 & 468 & 152 & 978 \\
\hline 09 & 0.22 & 610 & 351 & 2161 & 0.18 & 637 & 325 & 40 \\
\hline 10 & 0.18 & 459 & 280 & 721 & 0.19 & 476 & 290 & 451 \\
\hline 11 & 0.21 & 499 & 362 & 829 & 0.23 & 501 & 371 & 829 \\
\hline Average & 0.23 & 437 & 240 & 1179 & 0.23 & 448 & 246 & 574 \\
\hline
\end{tabular}

${ }^{\text {a }}$ Shown are variation of vertical velocities $\left(\sigma_{w}\right), N_{\max }^{o b s}$ and $N_{a v g}^{o b s}$ derived from the region restricted by the adiabatic criterion $\left(L W C / L W C_{a d i}>0.8\right)$ in the level part and from the in-cloud region as shown in Figure 2a (where the influence of mixing process is included). $N_{\max }^{o b s}$ is the 95th percentile of the observed $N$ distribution. $L W C_{a d i}$ is calculated depending on the temperature, pressure at each cloud height [Brenguier, 1991] as in the work by Peng et al. [2002]. The number of data points in the two data sets are listed in the 5 th and the 9 th columns. Average values over the 11 cloud cases are shown in the last row.

particles is dominated by $\mathrm{NH}_{4}^{+}$and $\mathrm{SO}_{4}^{2-}$, followed by $\mathrm{Na}^{+}$ and $\mathrm{Cl}^{-}$in the ASASP size range. On the basis of the ion balance, it is assumed that the soluble salt in the Aitken mode and the small accumulation mode is $\mathrm{NH}_{4} \mathrm{HSO}_{4}$, and $\mathrm{NaCl}$ in the large accumulation mode for the modeling. It is likely that the insoluble part contains some organic or crustal materials. Filter measurements detected some organic aerosols during RACE. Considering other likely coexisting components, the density of the insoluble particles is assumed to be $2 \mathrm{~g} \mathrm{~cm}^{-3}$ in all three modes. This value is the median of possible density of insoluble materials. A sensitivity test in terms of this assumption is discussed in section 4.2.

[30] Following the same procedure as outlined for cloud case 1, two more cloud cases from flight 13 and two from flight 18 of RACE were analyzed. For all of these five cloud cases, the aerosol spectra at cloud base were approximated with a trimodal lognormal distribution. The parameters of aerosol number concentration, aerosol size distribution and vertical velocity were determined from the Twin Otter 1-s measurements. The aerosol soluble fraction and chemical compositions were based on the nearest filter measurements below cloud base.

\subsection{NARE Data}

[31] Six cloud cases were selected from the NARE study (cloud cases 6-11, one each from flights 14, 16, 34, 36, 44 and 46) on the basis of the availability of measurements for cloud profiles, aerosol properties and vertical velocities. The data were analyzed in the same way as described for the RACE data except that all data stem from the Twin Otter only.

[32] Because the Twin Otter filter measurements were taken generally above the cloud, data obtained from this filter measurement cannot be used to represent the chemical properties of aerosols at cloud base for the parcel model simulation as we did for RACE. For NARE, Liu et al. [1996] showed the relationship between cloud condensation nuclei, size distribution and particle chemistry based on aerosol chemical and physical measurements at the coastal site of Chebogue Point in the vicinity of the aircraft flights. Their results indicated that $\mathrm{NH}_{4}^{+}$and non-sea-salt $\mathrm{SO}_{4}^{2-}$ ions are most strongly associated with $N_{a}$ of channels 2-7 of the PCASP, while $\mathrm{Na}^{+}$and $\mathrm{Cl}^{-}$are primarily associated with $N_{a}$ of channels $9-15$ of the PCASP. Therefore, as with RACE, the soluble parts of the Aitken mode and the small accumulation mode are assumed to be $\mathrm{NH}_{4} \mathrm{HSO}_{4}$ and $\mathrm{NaCl}$ is the dominant soluble component of the large accumulation mode for NARE.

[33] The soluble mass fraction of these aerosols is obtained by grouping all NARE clouds into two regimes [Li et al., 1996]. Cloud cases 6, 7, 9 and 10 have relatively low non-sea-salt $\mathrm{SO}_{4}^{2-}$ concentrations and total particle mass, thus a soluble fraction of 0.52 is calculated on the basis of the data of soluble ions provided by Li et al. [1996, Table 1] and the total aerosol particle mass calculated from the PCASP measurements. Cloud cases 8 and 11 are in the higher total particle mass regime, thus the calculated mass soluble fraction is 0.62 for these two cloud cases. The density of the insoluble part of aerosols is assumed to be $2 \mathrm{~g} \mathrm{~cm}^{-3}$ for all cloud cases during NARE as for RACE. In total, eleven cloud cases (five from RACE and six from NARE) are used for the comparison with the parcel model simulations.

\section{Results}

\subsection{Sensitivity of $N$ to Vertical Velocity}

[34] To examine the sensitivity of simulated $N$ to vertical velocity variations, the parcel model was run for each of the 11 cloud cases with two different scenarios. The first scenario uses the Gaussian distribution fitted to the $w$ distribution over the in-cloud region. The parcel model is run for each 5\% frequency of occurrence of $w$ plus one point at a relative frequency of 0.01 (crosses in Figure 4) to obtain a corresponding $N$ (i.e., $N(w)$, diamonds in Figure 4). The $N(w)$ for each $w$ is weighted by the relative frequency of occurrence of $w(p(w)$ in Figure 4) and integrated from a certain $w_{0}$ to obtain the $N_{\max }^{p d f}$ :

$$
N_{\max }^{p d f}=\int_{w_{0}} p(w) N(w) d w
$$

The $w_{0}$ is a threshold based on the following argument that only updraft velocities larger than some value (defined here as $w_{0}$ ) contribute to the nucleation of cloud droplets.

[35] Weighting the number concentration of the nucleated cloud droplets by the relative frequency of occurrence of $w$ (i.e., $p(w)$ in Figure 4$)$ is a representation of the potential influence of all the measured positive vertical velocities in the cloud. If all velocities from zero upward were used, then there would be a distribution of $N$ across the cloud that would have a larger number of smaller $N$ values and fewer higher $N$ values. In reality, $N$ is more similar for smaller and higher updrafts and indeed across updrafts and downdrafts; although some direct association of $N$ with stronger updrafts within a cloud is evident [e.g., Leaitch et al., 1996]. The vertical velocities in the types of clouds studied here change 


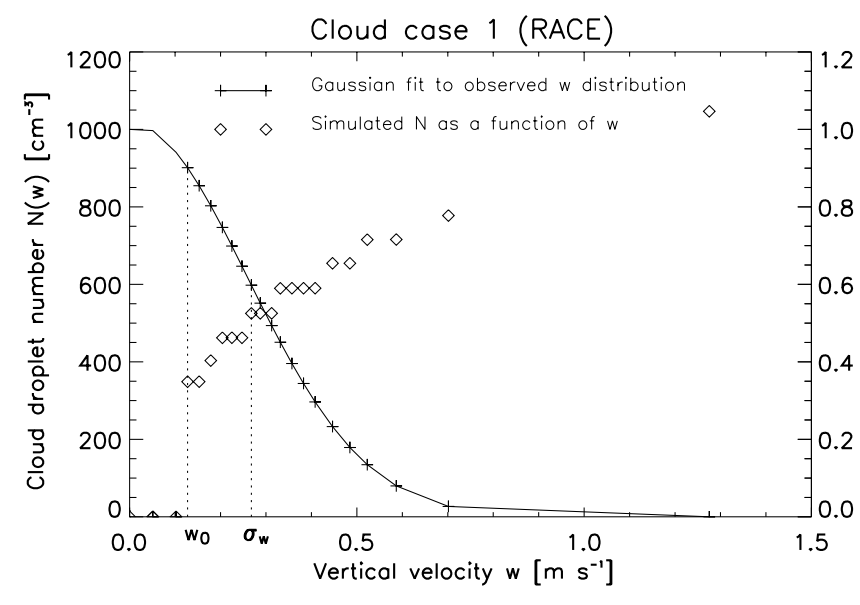

Figure 4. $N$ simulated in the PDF scenario for cloud case 1. The solid curve is the Gaussian distribution fitted to observed $w$ over the in-cloud region (see Figure $2 \mathrm{c}$ ). Twenty points evenly spaced with the relative frequency number $(p(w))$ of $w$ and one point at the relative frequency number of 0.01 are selected (crosses, right-hand side scale). The parcel model is run for each vertical velocity point to predict a corresponding $N(N(w)$, diamonds, left-hand side scale). The starting point for the integral to obtain the simulated $N$ in the PDF scenario is $w_{0}$ (cf. equation (1)); $\sigma_{w}$ is one standard deviation of the vertical velocity distribution.

with altitude [Feingold and Kreidenweis, 2002], and the value of $w$ at the point of measurement of $N$ is unlikely to be the same as the $w$ at the point at which $N$ was defined. The absence of a significant change in the mean $N$ over the entire cloud compared with the near-adiabatic portion (Table 2) is consistent with this interpretation. The smallest updrafts are the result of changes in the stronger vertical motions. They are not the updrafts that penetrate from well below cloud base up into the cloud. Hence it is expected that there is some distribution of higher updrafts that specify $N$ in the cloud. On this basis, $w_{0}$ is defined as the minimum value above which the application of the PDF of the $w$ values leads to simulated $N$ that are in agreement with the observed $N$. If $N$ is calculated on the basis of the complete right half PDF (i.e., $w_{0}=0$, cf. Figure 4 ), $N_{\max }^{p d f}$ is underestimated. The calculation of $N$ based on equation (1) is named as the PDF scenario.

[36] The second scenario simulates $N_{\max }^{\text {std }}$ using a single vertical velocity, which is proportional to the standard deviation (STD, i.e., $\sigma_{w}$ in Figure 4 ) of the $w$ distribution over the in-cloud region (e.g., $2 \sigma_{w}$ was taken to calculate the maximum $N$ in the work by Lin and Leaitch [1997]). Both the STD and PDF scenario represent the variation of in-cloud $w$ in the nucleation process. In the STD scenario, the characteristic vertical velocity in this study, $0.8 \sigma_{w}$, is selected by minimizing the difference between $N_{\max }^{\text {std }}$ and observed maximum $N$ (cf. Table 3 , the choice of the multiplier to get the characteristic $w$ is further discussed in section 4.3).

[37] Leaitch et al. [1996] showed that the cloud average $N$ $\left(N_{\text {avg }}\right)$ is related to the maximum $N\left(N_{\max }\right)$ in order to account for factors that reduce the adiabatic $N$ in clouds, including entrainment and precipitation scavenging. A sim- ilar relationship between $N_{\max }$ and $N_{\text {avg }}$ based on the measurement of our eleven cloud cases is derived here:

$$
N_{\text {avg }}=0.062 N_{\max }^{1.35}
$$

The correlation coefficient of this fit is 0.88 . Equation (2) is then used to derive $N_{\text {avg }}^{p d f}$ and $N_{\text {avg }}^{s t d}$ from $N_{\max }^{p d f}$ and $N_{\max }^{s t d}$, respectively.

[38] The comparison of simulated and observed $N$ are shown in Figure 5 (numerical values are listed in Table 4). Figures $5 \mathrm{a}$ and $5 \mathrm{~b}$ show $N$ obtained from the parcel model in the PDF scenario ( $N_{\max }^{p d f}$ and $N_{\text {avg }}^{p d f}$ ). Figures $5 \mathrm{c}$ and $5 \mathrm{~d}$ show $N$ obtained from the parcel model simulation in the STD scenario ( $N_{\max }^{\text {std }}$ and $N_{a v g}^{\text {std }}$ ) compared to the corresponding $N$ from observations ( $N_{\max }^{a b s}$ and $N_{a v g}^{o b s}$ respectively). The correlation coefficients $\left(r^{2}\right)$ between results in the STD scenario and observations are comparable to the PDF scenario but slightly higher. The percentage differences given in the last row of Table 4 indicate that $N$ simulated in the STD scenario agrees better with observed values for both maximum $N$ and averaged $N$. The values of $w_{0}$ are discussed in section 4.3.

\subsection{Sensitivity of $\boldsymbol{N}$ to Other Variables}

[39] The nucleation process in clouds is controlled by the number concentration, size distribution and chemical composition of the aerosol particles, in addition to the updraft velocity. In this study, the maximum variations in total aerosol number concentration measured within the wellmixed aerosol layer at cloud base are less than $30 \%$ for all cloud cases obtained during RACE and NARE. The activation fraction in the Aitken mode is up to $10 \%$. Thus only a few particles in the Aitken mode are activated in our simulations while most of aerosols are too small to reach a critical size [Pruppacher and Klett, 1997]. However, if the total number of aerosol particles in the two accumulation modes of the parcel model (which corresponds to $N_{a}$ measured with the PCASP) is varied by $30 \%$, simulated $N$ changes by almost the same factor. The activation fraction is more than $90 \%$ in the large accumulation mode but it only contributes to less than $1 \%$ of $N$ in all cloud cases. About

Table 3. Percentage Difference Between Simulated and Observed $N$ Averaged Over 11 Cloud Cases in the STD Scenario Using Different Characteristic Vertical Velocities ${ }^{\mathrm{a}}$

\begin{tabular}{lccc}
\hline & $D_{\max }, \%$ & $D_{a v g}, \%$ & Characteristic $w, \mathrm{~m} \mathrm{~s}^{-1}$ \\
\hline $0.4 \sigma_{w}$ & -18 & -23 & 0.09 \\
$0.6 \sigma_{w}$ & -6.4 & -9.5 & 0.14 \\
$0.8 \sigma_{w}$ & 5.7 & 8.8 & 0.18 \\
$1.0 \sigma_{w}$ & 7.6 & 11.3 & 0.23 \\
$1.2 \sigma_{w}$ & 17.6 & 26.0 & 0.28 \\
$1.4 \sigma_{w}$ & 25.0 & 38.3 & 0.32 \\
$1.6 \sigma_{w}$ & 33.2 & 51.1 & 0.37 \\
$1.8 \sigma_{w}$ & 44.8 & 71.8 & 0.41 \\
$2.0 \sigma_{w}$ & 61.7 & 105 & 0.46 \\
$2.2 \sigma_{w}$ & 133 & 246 & 0.51 \\
\hline
\end{tabular}

${ }^{\text {a }}$ The standard deviation of the $w$ distribution in clouds is $\sigma_{w}$. The product of a constant (ranging from 0.4 to 2.2 with interval of 0.2 ) and $\sigma_{w}$ is the characteristic vertical velocity applied in the STD scenario in the parcel model (we do not investigate characteristic vertical velocities smaller than $0.4 \sigma_{w}$ because these updraft velocities are comparable to the measurement uncertainty $\left(0.05 \mathrm{~m} \mathrm{~s}^{-1}\right)$ and they are too small to efficiently activate aerosol particles). $D_{\max }$ is the percentage difference between simulated maximum $N$ and the observed maximum $N . D_{a v g}$ is the percentage difference between simulated average $N$ and observed average $N$. 

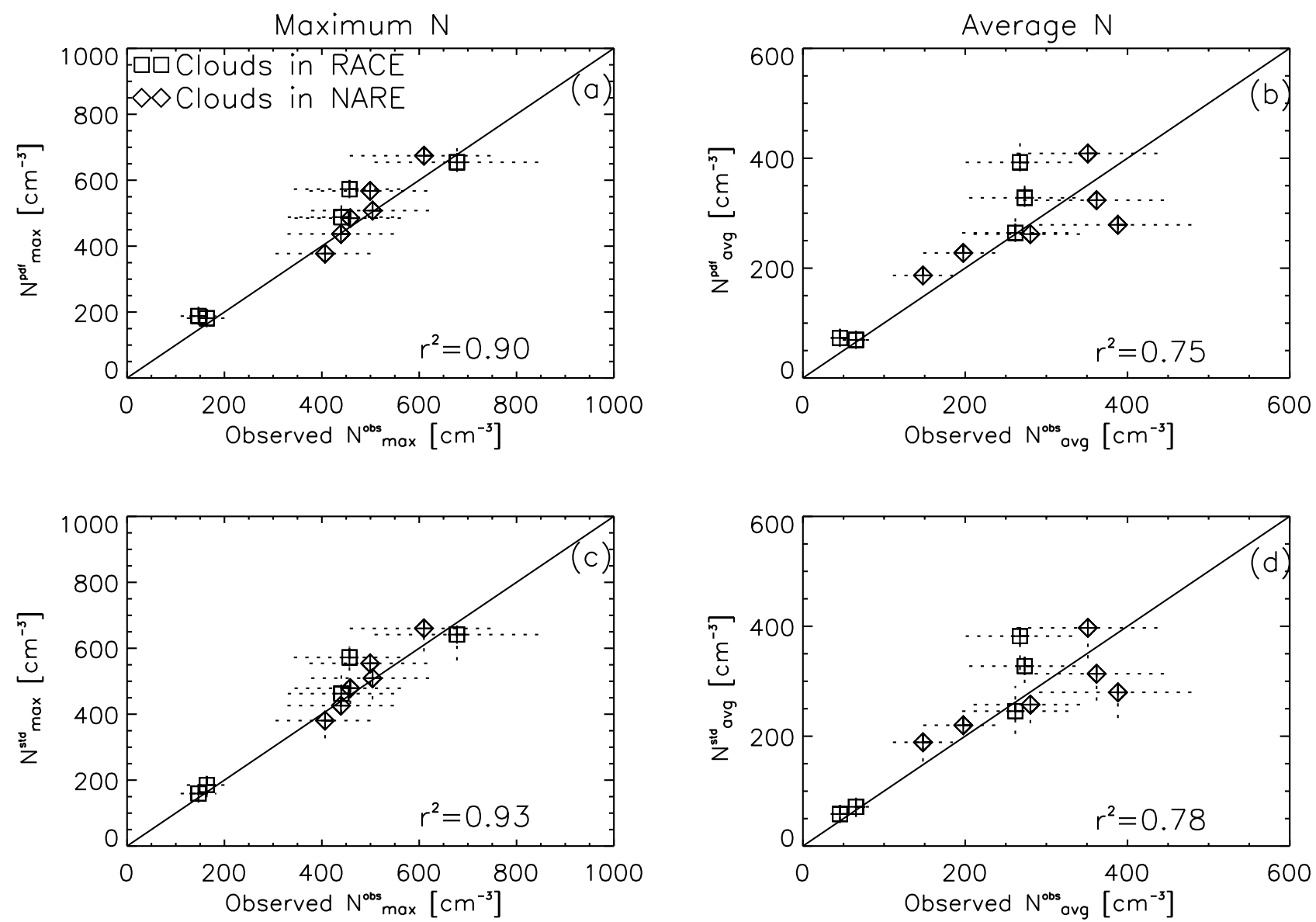

Figure 5. Comparison of parcel model-simulated $N$ and observed $N$. (a) $N$ simulated in the PDF scenario $\left(N_{\max }^{p d f}=\int_{w_{0}} p(w) N(w) d w\right.$, cf. Figure 4) compared with the observed maximum $N\left(N_{\max }^{o b s}\right)$. The vertical error bars indicate the simulated $N$ starting the integral from $w_{0} \pm 0.04 \mathrm{~m} \mathrm{~s}^{-1}$ (cf. section 4.3 , the errors are generally very small). (b) Observed averaged $N\left(N_{a v g}^{o b s}\right)$ compared with $N_{a v g}^{p d f}$, which is calculated from $N_{\max }^{p d f}$ using equation (2). (c) Simulated $N$ in the STD scenario using $0.8 \sigma_{w}\left(N_{\max }^{s t d}\right)$ compared with $N_{\max }^{o b s}$. The vertical error bars indicate the simulated $N$ using $(0.8 \pm 0.2) \sigma_{w}$ (see section 4.3). (d) $N_{a v g}^{s t d}$ calculated from $N_{\max }^{s t d}$ on the basis of equation (2) and compared to $N_{a v g}^{o b s}$. The correlation coefficient $\left(r^{2}\right)$ is given for each panel. All horizontal error bars indicate $\pm 25 \%$ of the measured $N$, which is the maximum uncertainty due to the instrumental error [Peng et al., 2002].

$60-90 \%$ of the particles in the small accumulation mode grow to form cloud droplets, and these dominate $N$ obtained from the parcel model simulations.

[40] Different chemical components $\left(\mathrm{NH}_{4} \mathrm{HSO}_{4}\right.$ and $\mathrm{NaCl}$ in this study) are assumed to be internal mixtures in the three size modes of the parcel model. We also ran the parcel model assuming that $\mathrm{NH}_{4} \mathrm{HSO}_{4}$ and $\mathrm{NaCl}$ are externally or internally mixed in the small accumulation mode (the main source of the nucleated cloud droplets) keeping the total number of aerosols fixed. The predicted $N$ of these two cases differs by less than $7 \%$, which indicates that the mixing state is not important when only $\mathrm{NH}_{4} \mathrm{HSO}_{4}$ and $\mathrm{NaCl}$ are considered. Varying the mixing state in the Aitken mode and the large accumulation modes causes up to $3 \%$ difference in $N$ because of the small activation fraction in the Aitken mode and relatively sparse number of aerosol particles in the large accumulation mode.

[41] Additionally, $N$ is predicted assuming either $\mathrm{NH}_{4} \mathrm{HSO}_{4}$ or $\left(\mathrm{NH}_{4}\right)_{2} \mathrm{SO}_{4}$ as the only soluble salt for all three modes, since ammonium sulfate rather than ammoni- um bisulfate is assumed in many GCMs. The resulting $N$ deviates from the ammonium bisulfate/sea salt mixture by less than $5 \%$ for either pure ammonium sulfate or pure ammonium bisulfate.

[42] The estimated soluble mass fractions of aerosol particles in this study are between 0.39 and 0.62 for all cases. These values are comparable with experimental results from a surface site in ACE-2 [Guibert et al., 2003]. Because of the lack of information on size distribution and chemical composition in the Aitken mode of the aerosol spectra (cf. Figure 3c), the soluble fraction in this mode may be underestimated if we use values taken from the filter data. A sensitivity test in terms of the soluble fraction in the Aitken mode is conducted. By increasing the soluble fraction in this mode up to 0.90 , the modelpredicted $N$ can be increased by up to $5 \%$. This is because the activation fraction in the first mode is low because of the small size of aerosol particles and the lower supersaturations in these clouds. Sensitivity to the soluble fraction in the two accumulation modes in the parcel model is 
Table 4. Numerical Values of Simulated and Observed $N$ for All Cloud Cases From RACE and NARE

\begin{tabular}{|c|c|c|c|c|c|c|c|}
\hline Cloud Case & $\sigma_{w}$ & $N_{\max }^{o b s}$ & $N_{\max }^{p d f}$ & $N_{\max }^{s t d}$ & $N_{a v g}^{o b s}$ & $N_{a v g}^{p d f}$ & $N_{a v g}^{s t d}$ \\
\hline \multicolumn{8}{|c|}{$R A C E$} \\
\hline 01 & 0.26 & 440 & 488 & 462 & 262 & 264 & 246 \\
\hline 02 & 0.38 & 678 & 655 & 642 & 267 & 393 & 382 \\
\hline 03 & 0.39 & 457 & 573 & 572 & 273 & 328 & 328 \\
\hline 04 & 0.26 & 147 & 188 & 160 & 46 & 73 & 58 \\
\hline 05 & 0.17 & 164 & 181 & 185 & 65 & 69 & 71 \\
\hline \multicolumn{8}{|c|}{ NARE } \\
\hline 06 & 0.18 & 504 & 508 & 509 & 388 & 279 & 280 \\
\hline 07 & 0.08 & 439 & 437 & 426 & 198 & 228 & 220 \\
\hline 08 & 0.14 & 407 & 378 & 381 & 148 & 187 & 189 \\
\hline 09 & 0.22 & 610 & 674 & 660 & 351 & 409 & 397 \\
\hline 10 & 0.18 & 459 & 485 & 479 & 280 & 262 & 257 \\
\hline 11 & 0.21 & 499 & 567 & 554 & 362 & 324 & 314 \\
\hline Average & 0.23 & 437 & 467 & 457 & 240 & 256 & 249 \\
\hline Difference & $\mathrm{n} / \mathrm{a}$ & $\mathrm{n} / \mathrm{a}$ & $8.6 \%$ & $5.7 \%$ & $\mathrm{n} / \mathrm{a}$ & $13.3 \%$ & $8.8 \%$ \\
\hline
\end{tabular}

${ }^{a}$ Values of $N$ are given in $\mathrm{cm}^{-3} ; \sigma_{w}$ is one STD of vertical velocity distribution over the in-cloud region (in $\mathrm{m} \mathrm{s}^{-1}$ ). $N_{\max }^{\text {obs }}$ and $N_{\text {avg }}^{\text {obs }}$ are observed maximum and average values of $N$ obtained for each cloud case. $N_{\max }^{p d f}$ is simulated with the parcel model in the PDF scenario $N_{\max }^{s t d}$ is simulated using $0.8 \sigma_{w}$ in the STD scenario. $N_{\text {avg }}^{\text {pdf }}$ and $N_{\text {avg }}^{\text {std }}$ are calculated from $N_{\max }^{\text {pdf }}$ and $N_{\max }^{\text {std }}$ respectively following equation (2). The last two rows are the averages over all 11 cloud cases and the average percentage difference between simulated and observed $N$ of each cloud case.

also tested. Increasing the soluble fraction to 0.90 (the highest value from the surface observation in the work by Guibert et al. [2003]) in the small and large accumulation modes, the model-predicted $N$ increases up to $30 \%$. Although we are more confident with the aircraft measurement of soluble fraction in the two accumulation modes in this study (because the filter measurements are most relevant to these particles) than in the Aitken mode, this $30 \%$ variation due to the change of the soluble fraction may substantially contribute to the uncertainty of the model-predicted $N$.

[43] A mode radius of 0.05 and standard deviation of 2 are assumed for the Aitken mode in the parcel model because of the lack of size distribution measurements in this size range. Some tests were conducted for sensitivity to the modal radii of this distribution $(0.003$ to $0.07 \mu \mathrm{m})$. It is assumed here that two chemical components dominate this mode: ammonium sulfate and carbonaceous aerosols. Soot (absorbing black carbon) aerosols are more likely present in relatively polluted maritime clouds in small size classes as reported by Hess et al. [1998]. For one test, it is assumed that the soot is insoluble and externally mixed. The mode radius and standard deviation of the soot distribution are varied between 0.012 and $0.03 \mu \mathrm{m}$ and between 1.55 and 2.0 respectively [Köpke et al., 1997; Lohmann et al., 2004]. The mode radius and standard deviation of the distribution of Aitken-mode ammonium sulfate is varied between 0.02 and 0.07 and between 1.5 and 2.24 respectively [Köpke et al., 1997; Lohmann et al., 2004]. The parcel model is run for these combinations of mode radii and standard deviations keeping the same total aerosol number in the Aitken mode. The model simulated $N$ changes by less than $1 \%$ on average; the activated fraction in this size mode is relatively small. Of the cases examined, the greatest fraction of Aitkenmode particles activated was $33 \%$ (particles $>0.025 \mu \mathrm{m}$ were activated; soot mode radius was $0.012 \mu \mathrm{m}$ ). The small sensitivity to changes in the Aitken mode lies in the fact that the particles in the Aitken distribution that do activate are the largest and constitute the upper tail of the distribution with the lowest number concentrations. Changes in mode radius and standard deviation do not modify the shape of the upper tail enough to result in significant changes in the number of activated Aitken particles.

[44] The insoluble material of aerosol particles can be carbonaceous or crustal components, or combinations of these. Their densities vary between 1 and $3 \mathrm{~g} \mathrm{~cm}^{-3}$. For insoluble densities of 1 and $3 \mathrm{~g} \mathrm{~cm}^{-3}$, the parcel model predicted the difference in $N$ up to $1 \%$.

[45] In this study, we run the parcel model with the water condensation coefficient of 1.0 , which was examined by Leaitch et al. [1986] using the same parcel model. A sensitivity test with three other values of the condensation coefficient is conducted. Values of 0.81 , the largest number tested by Snider et al. [2003], 0.01, the lowest value suggested by Pruppacher and Klett [1997] and 0.1 as an intermediate value are applied in the parcel model. The resultant change in the predicted $N$ can be up to $40 \%$ between the lowest and highest values. However, as shown by Davidovits et al. [2004], for typical temperatures characterizing tropospheric clouds, the measured values for the condensation coefficient are larger than 0.1. The activation fraction of aerosols is not sensitive to a relatively large coefficient as indicated by Davidovits et al. [2004] as was confirmed by the results of the sensitivity test here for values of 1.0 and 0.81 .

[46] To summarize, the largest uncertainties of the modelpredicted $N$ possibly stem from the measured soluble fraction of the accumulation mode aerosols and the water condensation coefficient assigned in the parcel model.

\subsection{Discussions}

[47] In the PDF scenario, we obtain simulated $N_{\max }^{p d f}$ by counting the nucleated $N$ only with vertical velocities higher than $w_{0}$. The value of $w_{0}$ is determined by comparing observed and simulated $N$ in the PDF scenario, which appears to be as the relative frequency number of $90 \%$ (cf. Figure 4). The average value of $w_{0}$ over 11 cloud cases is $0.11 \pm 0.04 \mathrm{~m} \mathrm{~s}^{-1}$.

[48] Because $w_{0}$ is determined by comparing observed and simulated $N$, the uncertainty of the measured $N$ (up to 

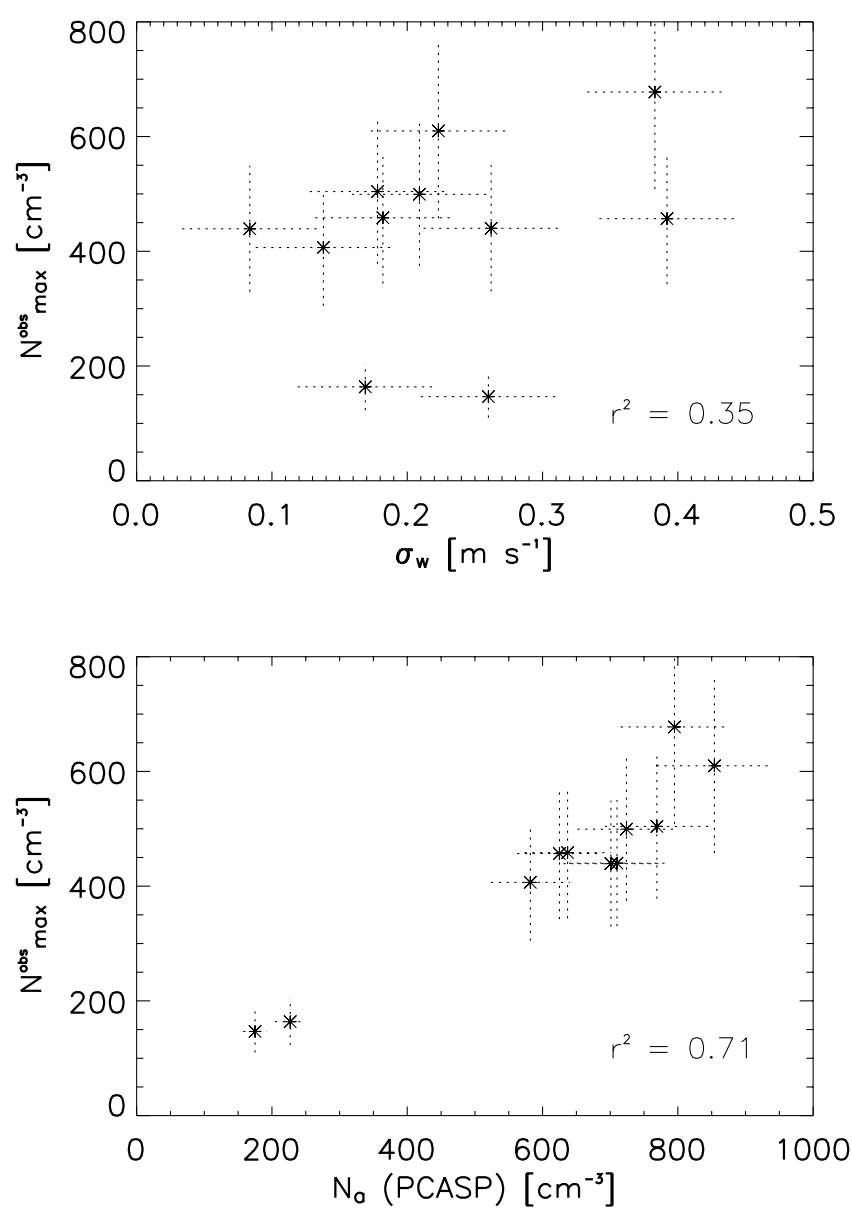

Figure 6. Dependence of observed maximum $N\left(N_{\max }^{o b s}\right)$ on the vertical velocity and the number concentration of the accumulation mode aerosols. (top) $N_{\max }^{\text {obs }}$ plotted versus the standard deviation of the $w$ distribution $\left(\sigma_{w}\right)$. (bottom) Dependence of $N_{\max }^{o b s}$ on the $N_{a}$ of the accumulation mode aerosols measured with the PCASP. The correlation coefficient in each panel is $r^{2}$. The measurement uncertainty for $N_{\max }^{o b s}$ is $\pm 25 \%$, for $N_{a}$ measured by PCASP is $\pm 10 \%$ and for $\sigma_{w}$ is $0.05 \mathrm{~m} \mathrm{~s}^{-1}$.

$\pm 25 \%$ [Peng et al., 2002]) contributes to the uncertainty of $w_{0}$. In the two field experiments analyzed in this study, the data resolution is about $50 \mathrm{~m}$ in the horizontal. These measurements averaged within 50-m flight segments tend to smooth out contributions of small-scale updraft velocity fluctuations to the number concentration of nucleated cloud droplets. This suggests that the parameter $w_{0}$ may also depend on the spatial resolution of observations on $w$.

[49] On the basis of the Gaussian distribution, $w_{0}$ can be related to $\sigma_{w}$ (cf. Figure 4):

$$
w_{0}=0.49 \sigma_{w}
$$

We show this relationship because $\sigma_{w}$ can be derived easily either from observational data or from parameterizations in the GCM. $w_{0}$ is an artificial parameter to be used to obtain the nucleated $N$ in terms of the PDF of $w$ distribution. In this study, it is selected on the basis of the comparison between simulated and observed $N$. Thus it depends not only on the dynamics but also on the aerosol microphysics since $N$ is determined by both turbulence in clouds and aerosol properties at cloud base. Figure 6 shows the dependence of observed maximum $N$ on the measured vertical velocity and the aerosol number concentration. $N_{\max }^{o b s}$ is mainly controlled by the number of accumulation mode aerosols measured using the PCASP, which counts particles with radii $>0.07 \mu \mathrm{m}$. The correlation coefficient between $N_{\max }^{o b s}$ and the PCASP-measured $N_{a}$ is $0.71 . N_{\max }^{o b s}$ is less dependent on the vertical velocity in clouds, which is represented by the standard deviation of the $w$ distribution over the in-cloud region (the correlation coefficient between $N_{\max }^{o b s}$ and $\sigma_{w}$ is $0.35)$.

[50] Leaitch et al. [1996] showed that $\sigma_{w}$ is a more important controlling factor for $N$ than the aerosol number concentration based on data taken from 14 flights during NARE (including the 6 cloud cases from NARE analyzed in this study). On the contrary the present results emphasize the dominant influence of the aerosol number concentration instead of $\sigma_{w}$. This may be due to the limited number of available cloud cases with detailed aerosol information from NARE as needed for this study. The NARE flights that are analyzed here do not exhibit the same variability of $w$ as the total number of flights that was analyzed by Leaitch et al. [1996] ( $w$ ranges from 0.08 to $0.22 \mathrm{~m} \mathrm{~s}^{-1}$ for the six NARE cases in this study (cf. Table 4) whereas in the work by Leaitch et al. [1996], $w$ varies between 0.05 and $0.8 \mathrm{~m} \mathrm{~s}^{-1}$ for 14 flights during NARE).

[51] To analyze to what degree observed $N$ is related to $\sigma_{w}$ in this study, we divided our 11 cloud cases into clean and polluted regimes based on observed $N_{a}$ with the PCASP (i.e., the two clouds with $N_{a}<300 \mathrm{~cm}^{-3}$ are clean, the other nine clouds are polluted; cf. Figure 6) and investigate the relationship again. In the polluted clouds with a relatively small variability of $N_{a}$, the correlation coefficient is increased to 0.45 between $N_{\max }^{o b s}$ and $\sigma_{w}$, indicating both $\sigma_{w}$ and PCASP-measured $N_{a}$ are contributing factors in the nucleation process although their relative importance may differ in different studies because of the different variabilities of measured $N_{a}$ and $\sigma_{w}$. Because $w_{0}$ is obtained in this study by comparing the difference between $N_{\max }^{o b s}$ and $N_{\max }^{p d f}$, both $\sigma_{w}$ and $N_{a}$ determine the value of $N_{\max }^{o b s}$ as shown in Figure 6. Therefore, besides the relationship obtained between $w_{0}$ and $\sigma_{w}$ (equation (3)), $w_{0}$ is potentially influenced by the aerosol properties, at least $N_{a}$ as well.

[52] The uncertainty of observed $N$ due to the influence of aerosol properties and the updraft velocity contributes to the uncertainty of $w_{0}$, because $w_{0}$ is determined by comparing observed and simulated $N$ in the PDF scenario. Considering the bias of $25 \%$ in the measured $N$ [Peng et al., 2002] as analyzed above, the uncertainty of $w_{0}$ is $\pm 0.2 \sigma_{w}$ (i.e., $\pm 0.04 \mathrm{~m} \mathrm{~s}^{-1}$ ), the consequent contribution to the uncertainty in $N$ simulated in the PDF scenario is up to $\pm 11 \%$ (as shown in Figure 5a).

[53] In the STD scenario, a value for $w$ equal to 0.8 times the standard deviation of the $w$ distribution $\left(\sigma_{w}\right)$ is the characteristic vertical velocity that results in the best agreement between simulated and observed $N$ (see Table 3 ). Taking the uncertainty of the measured $N( \pm 25 \%)$ into 
account, the characteristic $w$ giving the best agreement between simulated and observed $N$ is $(0.8 \pm 0.2) \sigma_{w}$.

\section{Conclusions}

[54] Reasonable agreement between the simulated and observed $N$ for 11 marine stratus cloud cases observed during RACE and NARE is found using a value of $0.8 \sigma_{w}$ as a surrogate for the variation of vertical velocities in the clouds studied here. Little improvement can be expected if the PDF of the vertical velocity distribution replaces one characteristic $w$ on the cloud scale for predicting $N$ more accurately. The uncertainty of the predicted $N$ due to the assumptions made for running the parcel model amount to up to $40 \%$ (section 4.2 ). The two biggest contributors to these uncertainties are related to assumptions on the soluble aerosol fraction and the condensation coefficient in the parcel model, but not the vertical velocity. The two representations for the variation of in-cloud vertical velocities (PDF and STD scenario) do not amplify or attenuate these aerosol related uncertainties individually. Thus the conclusion of the representation of the vertical velocity variations in this study is not significantly influenced by these aerosol related uncertainties.

[55] Comparing two different representations of the variation of in-cloud $w$ (the PDF scenario and the STD scenario in this study), for the PDF scenario, the variation of $w$ in the activation process is parameterized more realistically (including the introduction of a parameter $w_{0}$ to account for the inefficiency of small updraft velocities in the nucleation process). However, the relative difference and the correlation coefficient of the simulated and observed $N$ (cf. Figure 5 and Table 4) are such that the result in the STD scenario is as good as in the PDF scenario. Thus it is concluded that one single characteristic vertical velocity (proportional to the standard deviation of the $w$ distribution in clouds) is a good surrogate for the vertical velocity fluctuation for the nucleation process in the clouds studies here. The exact value of this characteristic vertical velocity may depend on the aerosol properties and dynamic factors for clouds in different regions, as well as on the accuracy with which $N$ can be measured.

[56] $\sigma_{w}$ indicates the width of the observed PDF of $w$ that is a measure of the level of turbulence in clouds. The subgrid-scale variation of vertical velocities used in the GCM to calculate $N$ is related to the in-cloud turbulence, thus it should be proportional to the standard deviation of the PDF of $w$ in the cloudy part of the grid box, which is so far parameterized in terms of the turbulent kinetic energy (TKE) [e.g., Lohmann et al., 1999]. Even when the $N$ parameterization is integrated over the PDF of $w$ to take the subgridscale $w$ variation into account, the PDF is constructed on the basis of the grid mean vertical velocity and the standard deviation obtained from TKE or the vertical diffusivity [e.g., Ghan et al., 1997]. Golaz et al. [2002] investigated simulation results from a PDF-based single column model and pointed out that the PDF of vertical velocities becomes important for convective clouds for predicting cloud properties. Additionally, Menon et al. [2003] compared different activation parameterization schemes applied in different single column models and showed that the vertical velocities, $L W C$, cloud geometry (cloud thickness) and the precip- itation formation in the climate model need to be resolved on a subgrid-scale to predict $N$ more accurately. Therefore more studies in terms of different cloud types are necessary to verify the representation of subgrid-scale vertical velocity fluctuations together with other microphysical quantities in climate models.

[57] The subgrid-scale variability of the vertical velocity is important not only for the parameterization of $N$, but also for radiative properties of clouds such as the cloud optical depth, cloud albedo and the effective radius [Feingold and Heymsfield, 1992; Menon et al., 2003]. The indirect effect of aerosols in stratocumulus clouds may strongly be related to vertical velocity variations [Feingold et al., 2003]. It is also of importance for cirrus clouds, and is not negligible when the indirect aerosol effect of ice clouds is evaluated [Kärcher and Ström, 2003]. Thus it is important to collect more cloud data with different aerosol sources in order to further test the sensitivity of $N$ to vertical velocity variations and its role in the model estimate of the indirect aerosol effect. To better characterize the fluctuation of vertical velocity in clouds, high-frequency measurements of vertical motions, together with measurements of microphysical and radiative quantities in the turbulent area in clouds, are needed.

[58] Acknowledgments. The authors thank Glen Lesins, Pamela Lehr and Betty Carlin for helpful discussions and suggestions. We also appreciate two anonymous reviewers for their constructional comments on this paper. This research is funded by the Killam Graduate Scholarship at Dalhousie University and the Canadian Foundation for Climate and Atmospheric Science (CFCAS).

\section{References}

Abdul-Razzak, H., and S. J. Ghan (2000), A parameterization of aerosol activation: 2. Multiple aerosol types, J. Geophys. Res., 105, 6837-6844.

Abdul-Razzak, H., and S. J. Ghan (2002), A parameterization of aerosol activation: 3. Sectional representation, J. Geophys. Res., 107(D3), 4026, doi:10.1029/2001JD000483.

Abdul-Razzak, H., S. J. Ghan, and Rivera-Carpio (1998), A parameterization of aerosol activation: 1. Single aerosol type, J. Geophys. Res., 103, $6123-6131$.

Boucher, O., and U. Lohmann (1995), The sulfate-CCN-cloud albedo effect: A sensitivity study with two general circulation models, Tellus, Ser. $B, 47,281-300$.

Brenguier, J.-L. (1991), Parameterization of the condensation process: A theoretical approach, J. Atmos. Sci., 48, 264-282.

Brenguier, J.-L., H. Pawlowska, L. Schüller, R. Preusker, J. Fischer, and Y. Fouquart (2000), Radiative properties of boundary layer clouds: Droplet effective radius versus number concentration, J. Atmos. Sci., $57,803-821$.

Chuang, C. C., J. E. Penner, K. E. Taylor, A. S. Grossmann, and J. J. Walton (1997), An assessment of the radiative effects of anthropogenic sulfate, J. Geophys. Res., 102, 3761-3778.

Cohard, J.-M., J.-P. Pinty, and C. Bedos (1998), Extending Twomey's analytical estimate of nucleated cloud droplet concentrations from CCN spectra, J. Atmos. Sci., 55, 3348-3357.

Davidovits, P., et al. (2004), Mass accommodation coefficient of water vapor on liquid water, Geophys. Res. Lett., 31, L22111, doi:10.1029/ 2004GL020835.

Fehsenfeld, F. C., P. Daum, W. R. Leaitch, M. Trainer, D. D. Parrish, and G. Huebler (1996), Transport and processing of $\mathrm{O}_{3}$ and $\mathrm{O}_{3}$ precursors over the North Atlantic: An overview, J. Geophys. Res., 101, 28,877-28,891.

Feingold, G., and P. Y. Chuang (2002), Analysis of the influence of filmforming compounds on droplet growth: Implications for cloud microphysical processes and climate, J. Atmos. Sci., 59, 2006-2018.

Feingold, G., and A. J. Heymsfield (1992), Parameterization of condensational growth of droplets for use in general circulation model, J. Atmos. Sci., 49, 2325-2342.

Feingold, G., and S. M. Kreidenweis (2002), Cloud processing of aerosol as modeled by a large eddy simulation with coupled microphysics and aqueous chemistry, J. Geophys. Res., 107(D23), 4687, doi:10.1029/ 2002JD002054 
Feingold, G., W. L. Eberhard, D. E. Veron, and M. Previdi (2003), First measurements of the Twomey indirect effect using ground-based remote sensors, Geophys. Res. Lett., 30(6), 1287, doi:10.1029/2002GL016633.

Ghan, S. J., C. C. Chuang, and J. E. Penner (1993), A parameterization of cloud droplet nucleation, part I: Single aerosol type, Atmos. Res., 30, $197-221$.

Ghan, S. J., C. C. Chuang, R. C. Easter, and J. E. Penner (1995), A parameterization of cloud droplet nucleation, part II: Multiple aerosol types, Atmos. Res., 36, 39-54.

Ghan, S. J., L. R. Leung, R. C. Easter, and H. Abdul-Razzak (1997), Prediction of cloud droplet number in a general circulation model, J. Geophys. Res., 102, 21,777-21,794.

Golaz, J.-C., V. E. Larson, and W. R. Cotton (2002), A PDF-based model for boundary layer clouds. Part II: Model results, J. Atmos. Sci., 59, $3540-3552$

Guibert, S., J. R. Snider, and J.-L. Brenguier (2003), Aerosol activation in marine stratocumulus clouds: 1. Measurement validation for a closure study, J. Geophys. Res., 108(D15), 8628, doi:10.1029/2002JD002678.

Hess, M., P. Koepke, and I. Schult (1998), Optical properties of aerosols and clouds: The software package OPAC, Bull. Am. Meteorol. Soc., 79, $831-844$.

Houghton, J. T., Y. Ding, D. J. Griggs, M. Noguer, P. J. van der Linden, X. Dai, K. Maskell, and C. A. Johnson (Eds.) (2001), Climate Change 2001: The Scientific Basis-Contribution of Working Group I to the Third Assessment Report of the Intergovernmental Panel on Climate Change, 881 pp., Cambridge Univ. Press, New York.

Kärcher, B., and J. Ström (2003), The roles of dynamical variability and aerosols in cirrus cloud formation, Atmos. Chem. Phys., 3, 823-838.

Köpke, P., M. Hess, I. Schult, and E. P. Shettle (1997), Global aerosol data set, Tech. Rep. 243, Max-Planck-Inst. for Meteorol., Hamburg, Germany.

Leaitch, W. R., J. W. Strapp, and G. A. Isaac (1986), Cloud droplet nucleation and cloud scavenging of aerosol sulphate in polluted atmospheres, Tellus, Ser. B, 38, 328-344.

Leaitch, W. R., et al. (1996), Physical and chemical observations in marine stratus during the 1993 North Atlantic Regional Experiment: Factors controlling cloud droplet number concentrations, J. Geophys. Res., 101, $29,123-29,136$

Li, S.-M., C. M. Banic, W. R. Leaitch, P. S. K. Liu, G. A. Isaac, X.-L. Zhou, and Y.-N. Lee (1996), Water-soluble fractions of aerosol and their relations to number size distributions based on aircraft measurements from the North Atlantic Regional Experiment, J. Geophys. Res., 101, 29,111-29,121.

Li, S.-M., K. B. Strawbridge, W. R. Leaitch, and A. M. Macdonald (1998), Aerosol backscattering determined from chemical and physical properties and lidar observations over the east coast of Canada, Geophys. Res. Lett. $25,1653-1656$

Lin, H., and W. R. Leaitch (1997), Development of an in-cloud aerosol activation parameterization for climate modelling, in Proceedings of the WMO Workshop on Measurement of Cloud Properties for Forecasts of Weather, Air Quality and Climate, pp. 328-335, World Meteorol. Organ., Geneva, Switzerland.
Liu, P. S. K., W. R. Leaitch, C. M. Banic, S.-M. Li, D. Ngo, and W. J. Megaw (1996), Aerosol observations at Chebogue Point during the 1993 North Atlantic Regional Experiment: Relationships among condensation nuclei, size distribution and chemistry, J. Geophys. Res., 101, 28,97128,990 .

Lohmann, U., J. Feichter, C. C. Chuang, and J. E. Penner (1999), Predicting the number of cloud droplets in the ECHAM GCM, J. Geophys. Res., 104, 9169-9198

Lohmann, U., G. Tselioudis, and C. Tyler (2000), Why is the cloud albedo-particle size relationship different in optically thick and optically thin clouds?, Geophys. Res. Lett., 27, 1099-1102.

Lohmann, U., B. Kärcher, and J. Hendricks (2004), Sensitivity studies of cirrus clouds formed by heterogeneous freezing in the ECHAM GCM, J. Geophys. Res., 109, D16204, doi:10.1029/2003JD004443.

Menon, S., et al. (2003), Evaluating aerosol/cloud/radiation process parameterizations with single-column models and Second Aerosol Characterization Experiment (ACE-2) cloudy column observations, J. Geophys. Res., 108(D24), 4762, doi:10.1029/2003JD003902.

Pawlowska, H., and J.-L. Brenguier (2000), Microphysical properties of stratocumulus clouds during ACE-2, Tellus, Ser. B., 52, 868-887.

Peng, Y., U. Lohmann, R. Leaitch, C. Banic, and M. Couture (2002), The cloud albedo-cloud droplet effective radius relationship for clean and polluted clouds from RACE and FIRE.ACE, J. Geophys. Res., 107(D11), 4106, doi:10.1029/2000JD000281.

Phinney, L., U. Lohmann, and W. R. Leaitch (2003), Limitations of using an equilibrium approximation in an aerosol activation parameterization, J. Geophys. Res., 108(D12), 4371, doi:10.1029/2002JD002391.

Pruppacher, H. R., and J. D. Klett (1997), Microphysics of Clouds and Precipitation, Springer, New York.

Seinfeld, J. H., and S. N. Pandis (1998), Atmospheric Chemistry and Physics, John Wiley, Hoboken, N. J.

Snider, J. R., S. Guibert, J.-L. Brenguier, and J.-P. Putaud (2003), Aerosol activation in marine stratocumulus clouds: 2 . Köhler and parcel theory closure studies, J. Geophys. Res., 108(D15), 8629, doi:10.1029/ 2002JD002692.

Squires, P., and S. Twomey (1960), The relationship between cloud droplet spectra and the spectrum of cloud nuclei, in Physics of Precipitation, Geophys. Monogr. Ser., vol. 5, edited by H. Weickmann, pp. 211-216, AGU, Washington, D. C

Whitby, K. T. (1978), The physical characteristics of sulfur aerosols, Atmos. Environ., 12, 135-159.

W. R. Leaitch, Meteorological Service of Canada, 4905 Dufferin Street, Downsview, ON, Canada M3H 5T4. (richard.leaitch@ec.gc.ca)

U. Lohmann, Department of Physics, Dalhousie University, Halifax, N. S., Canada B3H 3J5. (ulrike.lohmann@dal.ca)

Y. Peng, Max Planck Institute for Meteorology, Hamburg D-20146, Germany. (peng@dkrz.de) 